\title{
Research on Pump Primers for Friction Reduction of Wet-Mix Shotcrete Based on Precreating Lubricating Layer
}

\author{
Guoming Liu, ${ }^{1}$ Lianjun Chen, ${ }^{1,2}$ Weimin Cheng, ${ }^{1,2}$ and Yanan Huang \\ ${ }^{1}$ College of Mining and Safety Engineering, Shandong University of Science and Technology, Qingdao 266590, China \\ ${ }^{2}$ State Key Laboratory of Mining Disaster Prevention and Control Cofounded by Shandong Province and the Ministry of \\ Science and Technology, Shandong University of Science and Technology, Qingdao 266590, China \\ Correspondence should be addressed to Lianjun Chen; skyskjxz@163.com
}

Received 21 October 2016; Revised 15 February 2017; Accepted 20 February 2017; Published 5 March 2017

Academic Editor: Katsuyuki Kida

Copyright (C) 2017 Guoming Liu et al. This is an open access article distributed under the Creative Commons Attribution License, which permits unrestricted use, distribution, and reproduction in any medium, provided the original work is properly cited.

\begin{abstract}
Wet-mix shotcrete has lower water content even though looking wet which is generally less than $8 \%$ of total content. The inner surface of pipes will absorb water from fresh concrete to wet itself if concrete pump primers is not pumped early; meanwhile, the saturated concrete is transformed into the unsaturated concrete, and pipe blockage often occurs. In order to minimize the loss of water and wet pipes, a new type of pump primers was developed to precreate the lubricating layer that is one of the most dominant factors in determining the pumping capability, which would provide a cost-effective replacement for premium priced cement-based primers. Experiments were conducted to measure the viscosity, stability, and strength of mix solution during development stage. The optimal formula was obtained by orthogonal matching tests with $0.5 \%$ sodium stearate, $0.75 \%$ xanthan gum, $0.3 \%$ polyacrylamide, and $0.4 \%$ blender (mass ratio related to mix water). The pressure drop reduction of new primers was larger than that of common primers.
\end{abstract}

\section{Introduction}

Pumping process is the first phase ahead of spraying concrete to a substrate, which is very important for wet-mix shotcrete. However, blockages, leading to low work efficiency and causing the danger of pipe explosion in site, occur occasionally during pumping process, especially at the stage of startup if the lubricating layer that generally forms between the pipe and the material bulk was broken or not formed [1,2].

As shown in Figure 1, the lubricating layer is the major factor facilitating concrete pumping. The lubricating layer was firstly suggested in literatures [3,4]. And recently hot discussion about the pumping concrete mainly focuses on the lubricating layer and different assessment techniques to determine the properties of lubricating layer in the pumping process, including rheological measurement, UVP (ultrasonic velocity profiling), PIV (particle image velocimetry), and and use of colored concrete mixtures $[5,6]$. Therein, the thickness of lubricating layer estimated is commonly accepted with 1-5 $\mathrm{mm}$ [7-9].
Feys et al. $[10,11]$ noted that, according to the rheological parameters measured by a rheometer, the mix proportions of fresh concrete seem to influence the properties of lubricating layer and concrete would not be pumped without the existence of this lubricating layer. For example, the lower the water-binder ratio, the thinner the lubricating layer. An Ultrasonic Velocity Profiler (UVP) was used to monitor the thickness of lubricating layer and measure the velocity of concrete cross section in the full size pumping circuit with or without adding mineral admixtures [12-15]. Another technique reported in literature [16] with particle image velocimetry (PIV) was applied to estimate the velocity profile along the cross section of concrete flowing in a half open pipe test configuration. The numerical analysis was also used to estimate the thickness and rheological properties of lubricating layer under conditions of shear-induced particle migration and noted that rheological parameters varied throughout a cross section [17-19]. In addition, the technique with black concrete flowing after gray concrete was employed to identify the velocity profile of concrete in various pipes and 


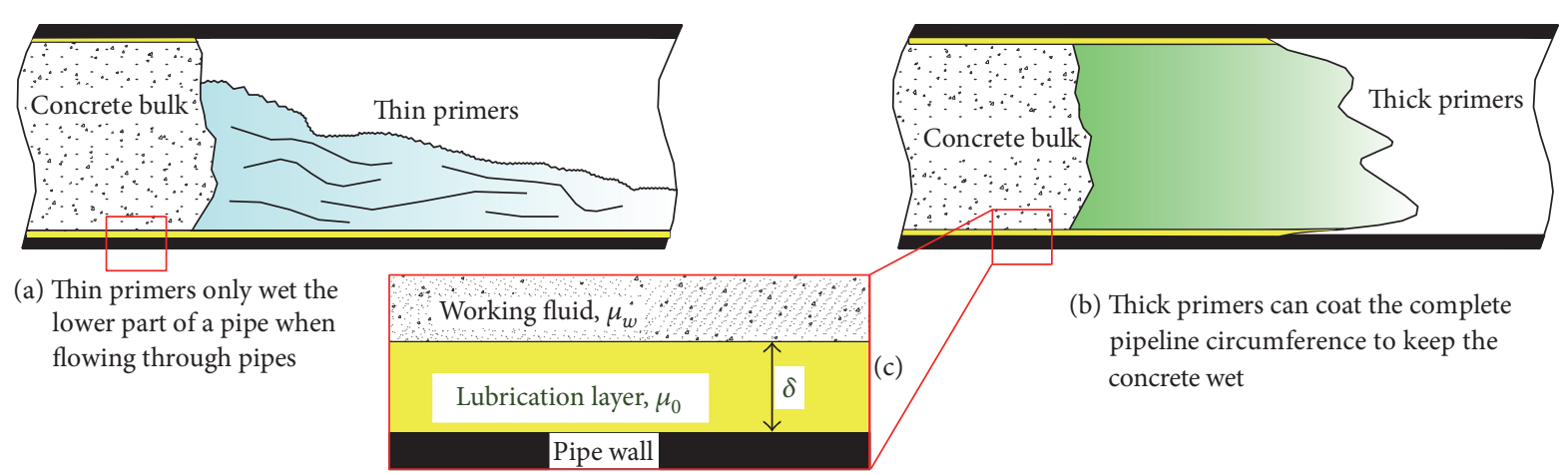

FIGURE 1: The formation of lubricating layer as primers flowing through pipes.

the slip layers over the pipe cross section were observed on a sawn surface along the central pipe axis [20]. Thus, various experimental methods for the characterization of lubricating layer are available in the pumping process.

However, there are few experimental studies on the precreating lubricating layer by pumping some viscosity materials (generally called concrete pump primers or lubricant for concrete) before pumping fresh concrete.

Considering that many different types of concrete which have different mix proportions and different rheological properties are used in construction, some of them may not form the lubricating layer (meaning bad pumpability) but can have shootability.

It is important, therefore, to precreate lubricating layer for the fresh concrete, especially for bad pumpability, to avoid blockage during startup pumping.

In order to avoid blockage, according to the requirement from Technical Specification for Pumping Construction of Concrete of China (JGJ/T10-95), the traditional method is to precreate the lubricating layer by pumping a certain quantity of grout or mortar before letting concrete into pipes to lubricate the inner wall of pipes where an annular film of grout is left as it flows through [21-23].

Kaplan et al. [1] have noted the most frequent blockages happen at priming due to the loss of cement paste at the pipe walls and the inertia that forces the coarse aggregates to leave the concrete front with each stroke of the pump, eventually making a saturated concrete an unsaturated concrete.

Nevertheless, the concrete pump primers that belong to the appendant of pumping concrete, generally consisting of grout or mortar, may cause some troubles in practical application. For example, the mortar as a pumping primer has lower strength than normal concrete. However, sometimes most workers falsely treat this mortar as the normal concrete and apply it into construction on site, which would bring potential quality hazard. For the long pumping pipes, once lubricating pipes normally need $2-3 \mathrm{~m}^{3}$ mortar which is a high cost and serious resource waste especially at the region lacking cement and sand resource. Also, the mortar transportation needs more manpower and material resources which would burden the unit in charge of construction in terms of budget.
Considering the opinions of low carbon, environmental protection, energy saving, and emission reduction, the lubricant for concrete appears gradually in markets instead of grout or mortar as concrete pump primers for pumping concrete in pipes. The synthetic pump primers were firstly introduced worldwide in the 90s [24].

Fritz-Pak Corporation has gained four US patents of synthetic primers which contain water thickeners and lubricating agents and can be also add to fresh concrete as a pumping aid without loss strength [25], but they are too expensive. Shijun et al. [26, 27] developed a kind of pumping lubricant consisting of viscous, lubricating, and diffluent materials, which can form lubricating layer with about $1 \mathrm{~mm}$ thickness after pumping. Literature [28] reported a type of lubricant consisting of hydroxypropyl methyl cellulose and polyethylene oxide and sodium carbonate, but it has poor solubility and can not obtain the efficiency of mortar used for lubricating pipes.

In other fields, some polymers or admixtures were used to reduce the frictional pressure drop in pipes. Nieuwenhuys added the drag-reducing polymers to a vertical multiphase flow to reduce the pipe pressure drop and studied the effect of the polymer on this flow [29].

The fiber extracted from Cocos nucifera (coconut), treated as drag-reducing agent in aqueous media flow, was used to reduce friction in pipe flow, which created a huge profit for the pipeline company [30]. Myoung investigated the effect of the mineral admixture on pipe flow of pumping concrete through analyzing the properties of lubricating layer and noted that the usage of blast furnace and silica fume having 5\% replacement could increase efficiency of pumping concrete [12].

However, there are few studies on lubricant for pumping concrete at home and abroad. In addition, most lubrication agents in markets have lower viscosity hardly coating the inner surface of pipes and being bad tolerance to concrete.

Hence, it is urgent to develop the new concrete pump primers (lubricant) with lower cost, better efficiency, and environmental protection. Here, we study in this work a new type of concrete pump primers to precreate the lubricating layer for reducing the pressure loss of pumping concrete.

The lubricating ingredient is necessary to reduce the friction between pipes and concrete bulk. However, the 
viscous content should be added to enhance the ability of coating pipes according to the following [31]:

$$
(1-\mathrm{DR})^{-1}=1+\frac{4 \delta}{R}\left(\frac{\mu_{w}}{\mu_{0}}-1\right)-\frac{2 \delta^{2}}{R^{2}}\left(\frac{2 \mu_{w}}{\mu_{0}}-1\right),
$$

where DR is drag reduction; $\mu_{w}$ is the viscosity of working fluid (concrete bulk); $\mu_{0}$ is the viscosity of a lubricating layer; $\delta$ is the thickness of lubricating layer, as shown in Figure 1(c).

We can obtain that drag reduction depends on $\mu_{w} / \mu_{0}$, that is, first-order DR $\sim \mu_{w} / \mu_{0}$, so it is adverse to use a lubricant that is more viscous than working fluid and more viscous lubricant experiences less drag reduction. We will discuss in this paper how the viscosity affects the friction. In addition, other materials were added in the new primers to improve some properties such as tolerance to concrete and solubility.

Using a series of experimental devices, for example, rotational viscometer and contact angle measurement, we measured the viscosity, friction reduction, and cohesion of the mixed solution. Finally, the new concrete pump primers were obtained based on orthogonal matching tests and applied in the case of a real size shotcreting pipes equipped with pressure gauges.

\section{Experimental Materials and Program}

\subsection{Experimental Materials}

2.1.1. Cement and Aggregates. Ordinary Portland cement (P.O 42.5, purchased from China United Cement Qufu Co., Ltd.) was used in the research with a fineness of $3170 \mathrm{~cm}^{2} / \mathrm{g}$ and a specific gravity of 3.15 . No composite material is added. Coarse aggregates were crushed gravel with a maximum size of $10 \mathrm{~mm}$. River sand was used as fine aggregate. Both aggregates comply with the requirements of the ISO standard in national standard GB/T17671-1999.

2.1.2. Constituents of the New Type Primers. The major function of a primer is to lubricate the inner wall of pipes to reduce the friction between concrete bulk and pipe wall, so the lubricating content is necessary. Another function of a pump primer is to coat the inner surfaces of pipe, so viscosity, related to the thickness of a material and its ability to flow, is an important property because thick materials run down more slowly than thin materials and can coat the complete pipeline circumference to keep the concrete wet while a thin material will run very fast and only wet the lower part of a pipe when flowing through pipes, as shown in Figures 1(a) and $1(\mathrm{~b})$.

Certainly, in order to retain the stability of artificial primers and enhance the solution rate, stabilizer and blender are usually added in mixture. Therefore, a good lubrication agent for pumping concrete should consist of various function materials like viscous, lubricating, and stabilized constituents. Based on the related patents and literatures published at domestic and overseas, four raw materials were initially selected and experimented, which are represented as A, B, C, and D [24-26, 32].

Specifically, Material A is sodium stearate belonging to lubricating component, which is generally used for the synthesis of laundry soap and lubricant [33-36]; moreover, sodium stearate considerably reduces the wear of steel construction and hot water or alcohol dissolves it well [37]. Therefore, it can be known that sodium stearate is an ideal component of lubricant.

Material B is xanthan gum considered as industrial monosodium glutamate which is a kind of safe food additive and also an efficient thickener with lower content. Its viscosity is 100 times higher than gelatin with $1 \%$ concentration in water. Xanthan gum belongs to polysaccharides which can control the rheology and network structure of the aqueous continuous phase by increasing viscosity and yield stress $[38,39]$. Material B is highly soluble in water, especially in cool water, and also in sodium hydroxide solution, which indicates that xanthan gum has strong resistance against the adverse environment of low temperature and alkali [40].

Material C, polyacrylamide, is a linear high molecular polymer that can be dissolved in water to form long, tortuous chains that form bridges to link two or more materials together, finally presenting good viscosity and cohesiveness [41]. When $\mathrm{C}$ mixes with $\mathrm{B}$, a considerably viscous material is generated due to the "bridging" effect, which can increase thickness enough to coat the complete inner surface of pipes and it is nontoxic [42]. As a kind of good drag-reduction agent, a small amount of polyacrylamide can reduce the resistance by $50-80 \%$ in water [43].

As a kind of blender, Material D, absolute ethyl alcohol, can improve the solubility of lubricating materials, which is also nontoxic and inexpensive. Tap water was used to mix the experimental materials.

The solutions above used in this experiment were all analytically pure and were purchased from Qingdao Jingke Chemical Co., Ltd.

2.1.3. Existing Primers. A common powdery lubricating agent for pumping concrete (purchased from Qingdao Meilong Mortar Technology Co. Ltd) was employed in the experiments to compare the lubricating efficiency.

\subsection{Experimental Program}

2.2.1. Measurement of Viscosity and Coating Weight. Viscosity tests were conducted using a NDJ-1 rotational viscometer (Figure 2) after the lubricating agent dissolving into water uniformly in a breaker with stir.

In addition, in order to determine the amount of material that coat the inner wall of pumping steel pipe, a part of steel pipe with $500 \mathrm{~mm}$ long and $64 \mathrm{~mm}$ inner diameter was taken which was blocked at one end by using a circular steel plate with a pipe clamp, as shown in Figure 3.

The dry pipe was firstly weighed as $M_{1}$. Secondly, the wet pipe that had been filled with primer sand then left to drip for 5 seconds was weighed as $M_{2}$. The amount of the coating was finally calculated by the method of $M_{2}$ minus $M_{1}$. The coating weight $(\mathrm{CW})$ as follows: $\mathrm{CW}=\left(M_{2}-M_{1}\right) / S$, where $S$ is the inner superficial area of total steel pipes. The data was finally obtained by averaging three measured values.

2.2.2. Measurement of Stability against Concrete. Fresh wetmix shotcrete was cast into a flat disk and then a drop of 


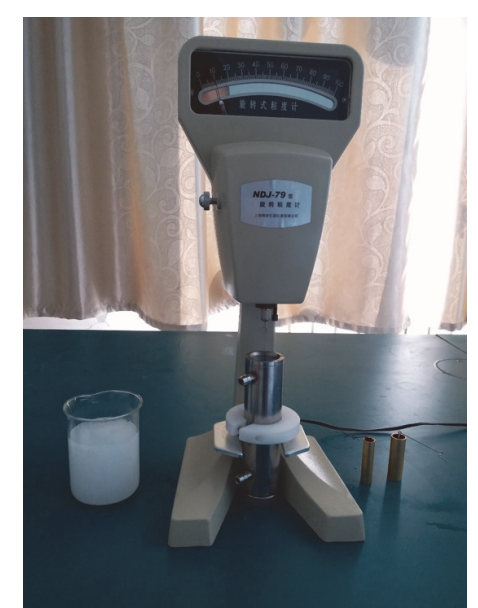

FIGURE 2: NDJ-1 rotational viscometer.

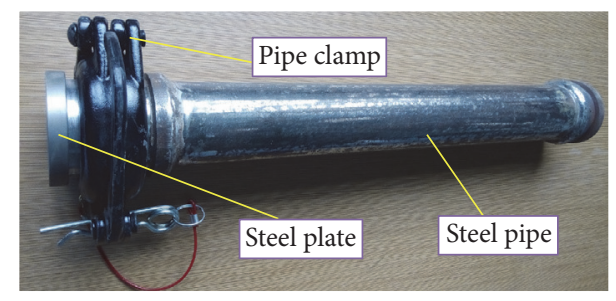

FIGURE 3: Pipe used for measuring coating weight.

solution was dripped in the interface of concrete after 1-day water cure as shown in Figure 4(a); the purpose of 1-day water cure is to simulate the similar environment between fresh concrete pipes and lubricant under the condition of concrete disk that can be moulded to conduct the contact angle experiments. Contact angle measurement was used to characterize the stability of lubricant solutions against cement paste. A bigger equilibrium contact angle between the solution and concrete relates to a better stability, as shown in Figure 4(b); contact angle $\theta_{2}>\theta_{1}$ means that solution $B$ has larger stability than solution A against concrete.

2.2.3. Measurement of Friction Reduction Effect. To simplify the experiments of measuring friction reduction, a smallscale experimental platform was constructed, which consists of a tensiometer, a concrete sample after $28 \mathrm{~d}$ cure, and a rubber plate. Considering the applicability and veracity of data obtained from this experimental platform, two comparative measurements were conducted. The surface morphology was observed conducted by 3D Leica Digital Microscopy (Model: DVM5000HD), between inner face of steel pipe and rubber plate, between fresh concrete in real scale pipes and concrete sample $(40 \times 40 \times 160 \mathrm{~mm})$ used for the test platform. It can be seen in Figures 5(a) and 5(b) that the max elevation and surface morphology of steel pipe inner wall are close to the case of the rubber plate. Although the max elevation of fresh concrete represented by the concrete after 1-day water cure in Figure 4(a) is relatively lower than that of concrete sample used for friction reduction test, the surface morphologies of both of them are extremely similar as shown in Figures 5(c) and $5(\mathrm{~d})$.

The tensiometer was connected with a concrete sample by wirerope and the lubricant solution was coated on the surface of rubber plate with 1-3 mm thickness. During the process of measuring friction reduction between concrete and rubber plate, the concrete sample was pulled by the tensiometer at a constant speed about $0.17 \mathrm{~m} / \mathrm{s}$. The tension value was read in the tensiometer and the final tension value was gained by averaging three measure values. Therefore, for the given experimental plate, the friction reduction FR is taken to be one minus the ratio of the tension required to pull the concrete sample $F$ to the case without a lubricating agent (i.e., dry rubber plate) $F_{0}, \mathrm{FR}=1-\left(F / F_{0}\right)$.

\subsubsection{Measurement of Strength of Concrete. A WDW 3100} computer-controlled electric universal test machine was used to measure the strength of concrete samples. Before shotcreting, the concrete samples were cast in the module $100 \mathrm{~mm} \times$ $100 \mathrm{~mm} \times 100 \mathrm{~mm}$. The compressive strength of the shotcrete was measured according to national standard GB50086-2001 Specifications for Bolt-Shotcrete Support.

\section{Results and Discussion}

3.1. Determination of the Range for Lubricating Ingredient. The optimum concentration range of materials A should be determined by experiments because it is the primary lubricating ingredient of the new pump primers. Note that $\%$ following means the mass ratio of one to water.

As we all know, sodium stearate is slightly soluble in cool water but hot water or ethyl alcohol. Hence, in order to improve the solubility of sodium stearate under the condition of normal water temperature, ethyl alcohol as a kind of blender was added in solution. According to previous tests, firstly, sodium stearate with $0.5 \%$ concentration was prepared and then mixed with ethyl alcohol with a concentration ranging from 0 to $1 \%$. The mixed solution was blended for $20 \mathrm{~s}$ at $968 \mathrm{r} / \mathrm{min}$.

As can be seen from Figure 6, with the increasing of the content of alcohol, the powder adhering on the inner wall of beakers and air bubbles generated both gradually became less when stirring the sodium stearate solution, which indicated that sodium stearate has a better solubleness with more alcohol. Hence, in the next experiments, $0.3 \%$ alcohol was used as the blender which shows a better property of promoting sodium stearate dissolving in water.

Then, an aqueous solution with sodium stearate ranging from 0 to $2 \%$ and alcohol with $0.3 \%$ was prepared as a primeval lubricant.

As can be seen from the test results shown in Figure 7, with increasing the content of sodium stearate, the apparent viscosity declined slightly and then increased; however, FR increased gradually when the content of sodium stearate decreased by $1 \%$ and then declined gently; that is, too much sodium stearate is bad for reducing the friction and the appropriate range should be almost determined between $0.5 \%$ and $1 \%$. But the rank of viscosity among the range 


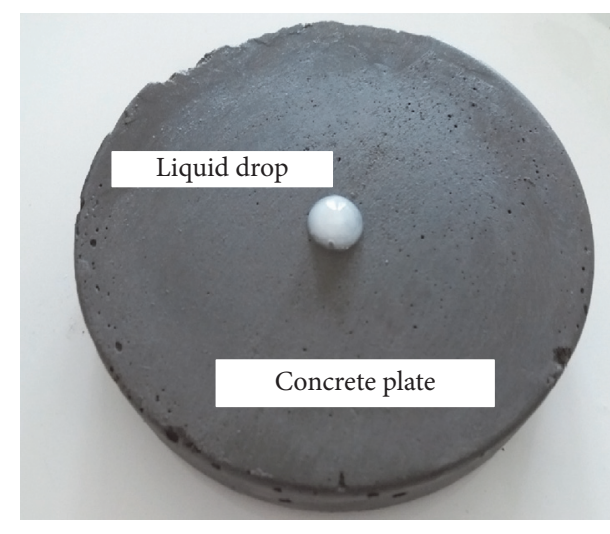

(a)
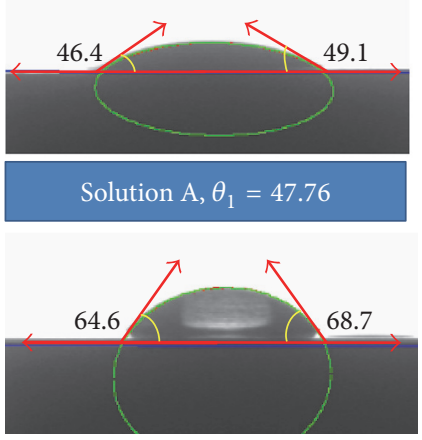

Solution $\mathrm{B}, \theta_{2}=66.64$

(b)

Figure 4: Contact angle measurement.

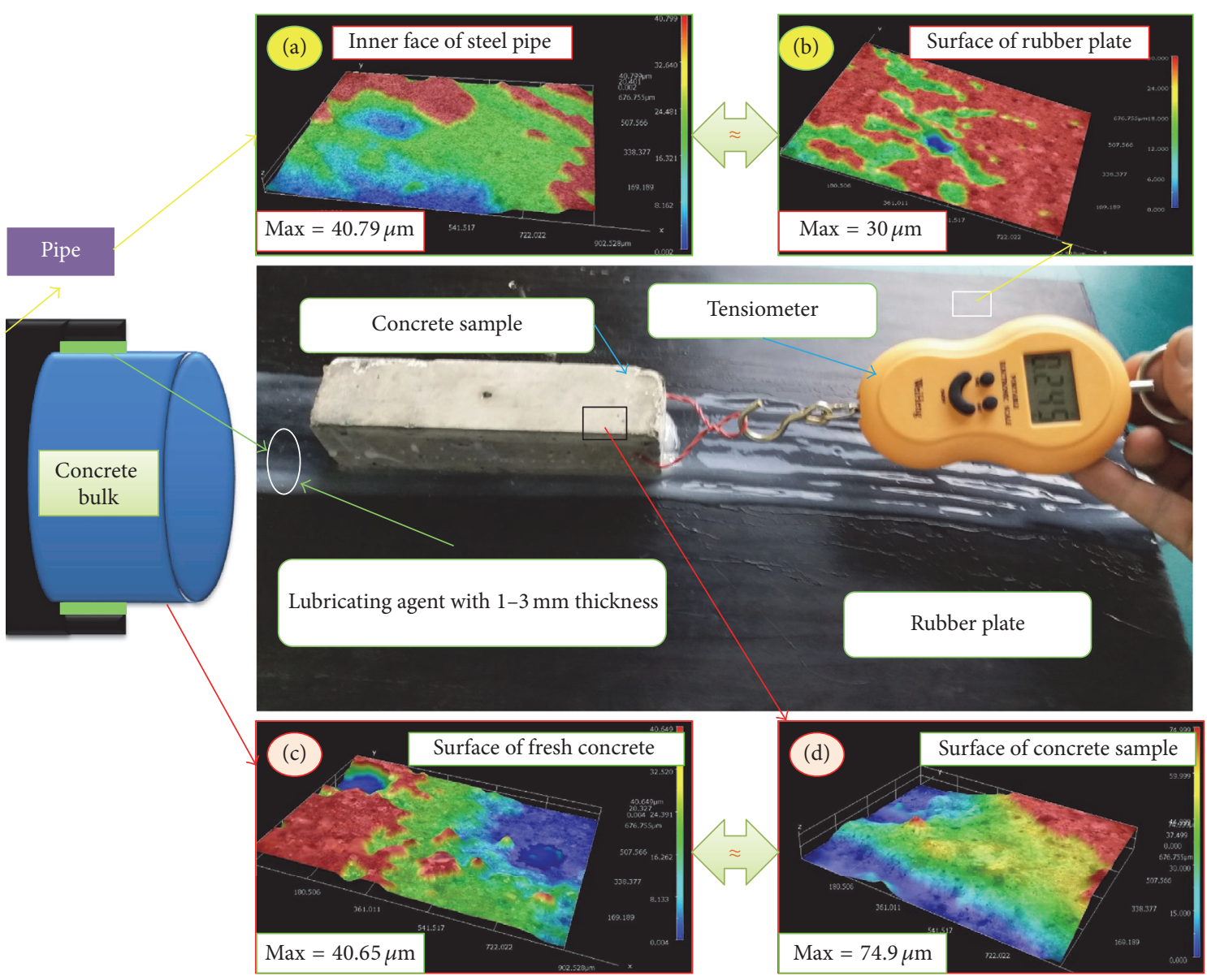

FIGURE 5: Measurement of the friction reduction and comparison of surface morphologies.

determined is nearly equal to clean water and too low to coat the inner wall as flowing through pipes.

\subsection{Combination of Sodium Stearate and Xanthan Gum.} In order to improve the viscosity of new primers, due to larger viscosity easily creating a thermodynamically stable film after coating a piece of steel pipe used in pumping concrete, xanthan gum as a thicker, ranging from $0.25 \%$ to $2 \%$ according to the preliminary test results, was added in the solution of $0.5 \%$ sodium stearate and $0.3 \%$ alcohol. The apparent viscosity, coating weight, FR, and contact angle were measured and calculated. Results are shown in Figure 8.

Figure 8 indicates that increasing xanthan gum improved the coating weight and apparent viscosity obviously while 


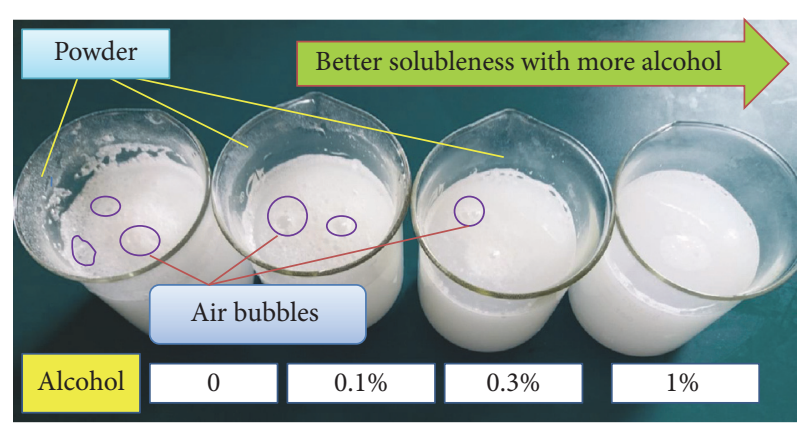

FIGURE 6: The mixture condition of sodium stearate and alcohol with different concentration.

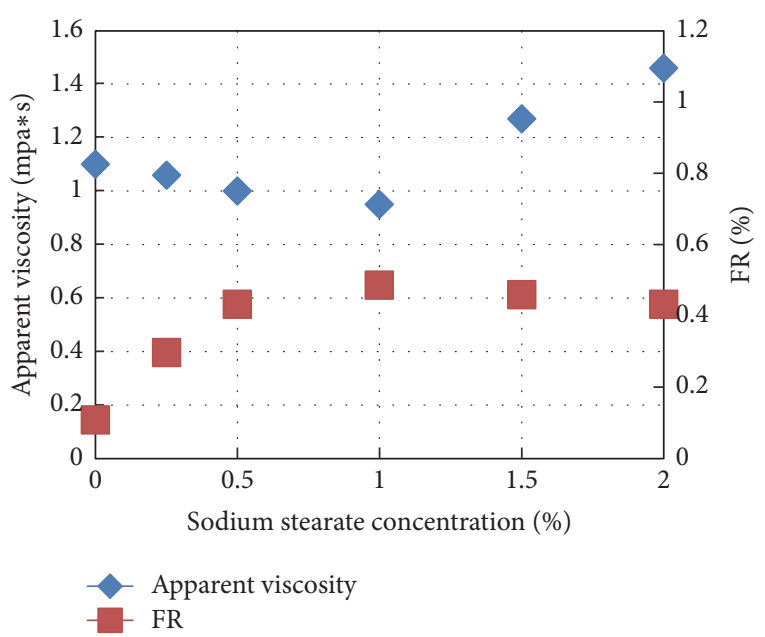

Figure 7: Effect of sodium stearate concentration on FR and apparent viscosity.

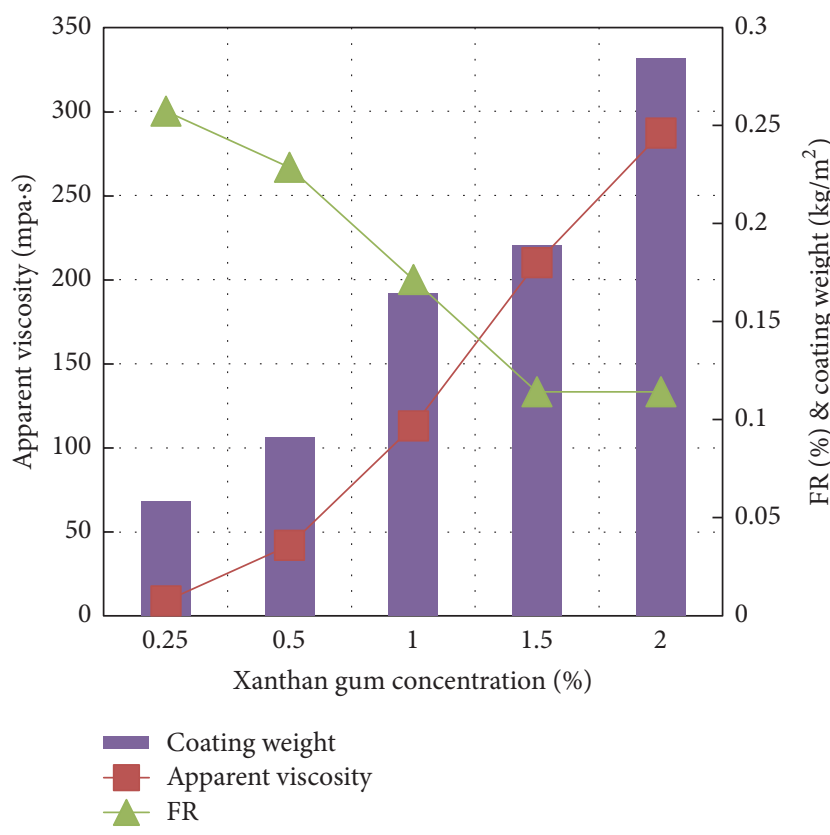

FIGURE 8: The performance change of combination of sodium stearate and xanthan gum.

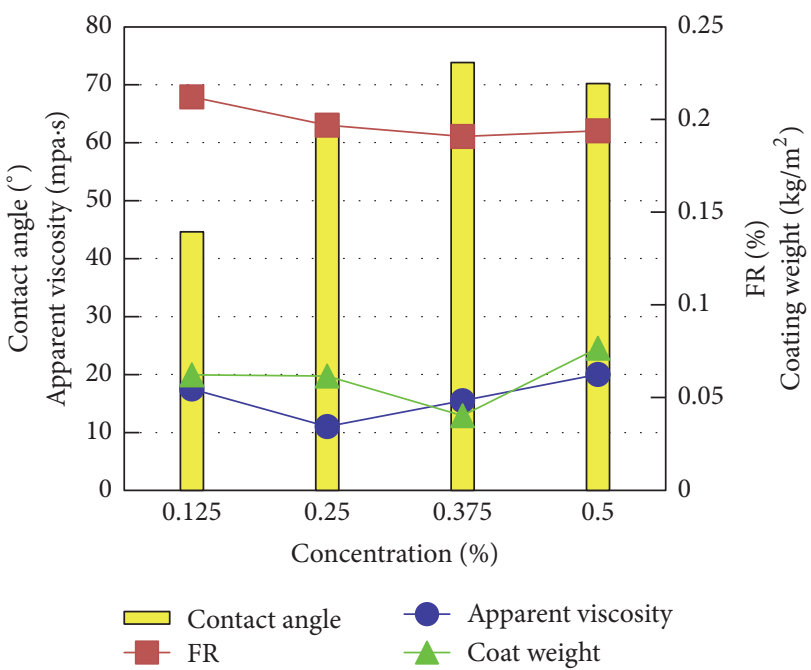

FIGURE 9: The performance of combination of sodium stearate and polyacrylamide.

decreased FR. From the pipe coating results, we can see a correlation between the viscosity and the amount of coating weight. So it is possible to say that the higher viscosity material creates a better coating of pipes or hoses.

According to the primeval tests, the apparent viscosity of cement mortar was $912-746 \mathrm{mpa} \cdot \mathrm{s}$ with $0.45-0.55$ watercement ratio, which is generally larger than that of lubricant solution. Hence, it also can be known in Figure 8 that FR declined with increasing apparent viscosity, which proves that less viscous lubricant experiences relatively large friction reduction related to equation (1) reported in [31]. From the perspective of both FR and coating weight, the concentration of xanthan gum with $0.5 \%-1 \%$ is advised. However, the contact angle measured of this experimental solution with $0.25 \%-2 \%$ xanthan gum fluctuated between $30^{\circ}$ and $50^{\circ}$, which shows lower stability against concrete.

3.3. Combination of Sodium Stearate and Polyacrylamide. The addition of polyacrylamide was to improve its stability, because it is necessary that new primers are immiscible with concrete and that the system is thermodynamically stable [44]. When polyacrylamide content was increased ranging $0.125-0.375 \%$, the contact angle increased up to $74.3^{\circ}$ (see Figure 9). However, the increasement of polyacrylamide content decreased FR, and the susceptibility of polyacrylamide to both apparent viscosity and coating weight was small. Hence, it can be known that polyacrylamide can efficiently increase contact angle and improve its stability.

3.4. Orthogonal Matching Tests. According to the previous experiments of the combination of sodium stearate with alcohol, xanthan gum, and polyacrylamide, the optimum range for the concentration of four ingredients was basically determined. However, the effect of the combined action of four materials in a mixed solution was uncertain. Therefore, orthogonal tests were applied to evaluate the optimum mixture of the combination of the four materials. Three levels 
TABLE 1: Orthogonal test proposal.

\begin{tabular}{lcccc}
\hline Number & A (\%) & B (\%) & C (\%) & D (\%) \\
\hline 1 & 0.25 & 0.5 & 0.1 & 0.2 \\
2 & 0.25 & 0.75 & 0.2 & 0.4 \\
3 & 0.25 & 1 & 0.3 & 0.6 \\
4 & 0.5 & 0.5 & 0.2 & 0.6 \\
5 & 0.5 & 0.75 & 0.3 & 0.2 \\
6 & 0.5 & 1 & 0.1 & 0.4 \\
7 & 0.75 & 0.5 & 0.3 & 0.4 \\
8 & 0.75 & 0.75 & 0.1 & 0.6 \\
9 & 0.75 & 1 & 0.2 & 0.2 \\
\hline
\end{tabular}

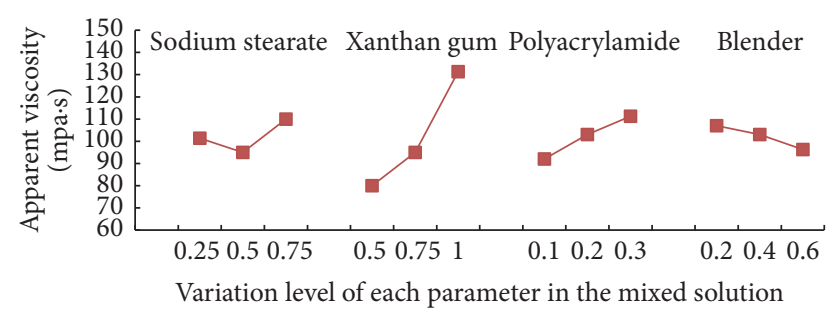

FIGURE 10: Main effect plot for apparent viscosity.

were set in which A was tested at $0.25 \%, 0.5 \%$, and $0.75 \%, \mathrm{~B}$ at $0.5 \%, 0.75 \%$, and $1 \%$, and $\mathrm{C}$ at $0.1 \%, 0.2 \%$, and $0.3 \%$, while $\mathrm{D}$ was presented at $0.2 \%, 0.4 \%$, and $0.6 \%$. The orthogonal test proposal is shown in Table 1 .

Given the interaction of each material in mixed solution, analysis of variance (ANOVA) technique was used at a 0.05 level of significance to examine the variation in the measured properties of the mixed solution. The main effect graphs from Figures 10-13 were plotted for apparent viscosity, coating weight, FR, and contact angle to determine the best possible testing conditions of the primers properties. And according to the analysis, the best mix proportions of the target properties are shown in Table 2. In order to determine the degree of contribution of different material to the measured response, the contribution percentages shown in Figure 14 were obtained. That is, the higher the contribution percent, the more the contribution of the variable to the particular response.

Under the condition of interaction between them in mixed solution, the following can be seen from the results of Figures 10-14.

Figure 10 shows that increasing the content of sodium stearate and polyacrylamide improved the apparent viscosity of mixed solution while increasing blender decreased it. The response of apparent viscosity is convenient to the results in Section 3.2. The most influencing factor on apparent viscosity was xanthan gum up to $80 \%$ contribution and the contribution rank of each material was $\mathrm{B}>\mathrm{C}>\mathrm{A}>\mathrm{D}$, shown in Figure 14. The mix proportion at $0.75 \% \mathrm{~A}, 1 \% \mathrm{~B}, 0.3 \%$ $\mathrm{C}$, and $0.2 \% \mathrm{D}$ was obtained as the optimal conditions for maximum apparent viscosity.

According to Figure 11, coating weight increased with the increasement of xanthan gum and blender content, with
TABLE 2: Optimal mix-design proportions for properties of new primers.

\begin{tabular}{lcccc}
\hline Optimal mix proportions & $\mathrm{A}(\%)$ & $\mathrm{B}(\%)$ & $\mathrm{C}(\%)$ & $\mathrm{D}(\%)$ \\
\hline Apparent viscosity & 0.75 & 1 & 0.3 & 0.2 \\
Coating weight & 0.25 & 1 & 0.3 & 0.6 \\
FR & 0.75 & 0.75 & 0.3 & 0.2 \\
Contact angle & 0.5 & 1 & 0.3 & 0.2 \\
\hline
\end{tabular}

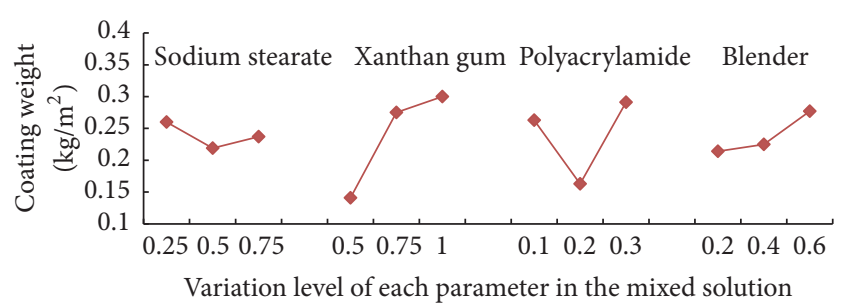

Figure 11: Main effect plot for coating weight.

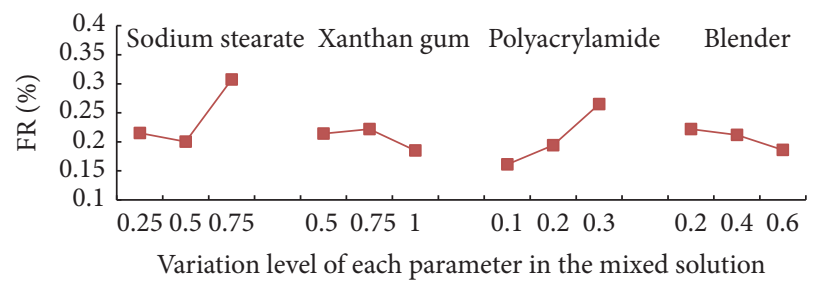

Figure 12: Main effect plot for FR.

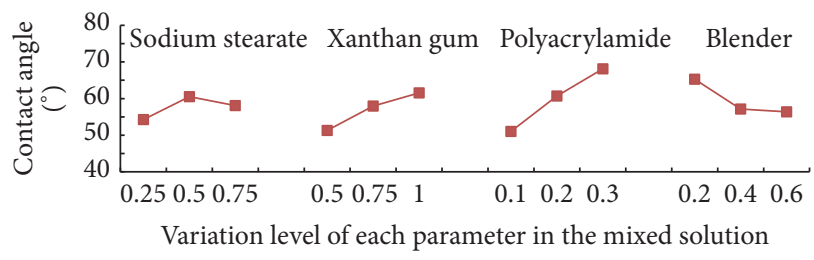

Figure 13: Main effect plot for contact angle.

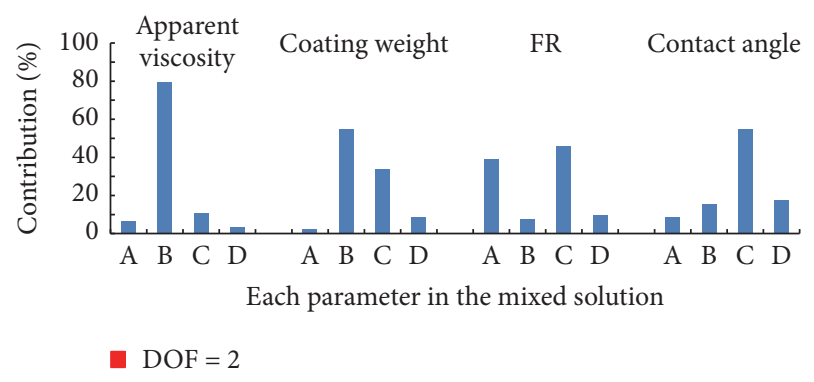

FIgURE 14: The contribution of different material to the measured response. The red box represents the degree of freedom in the analysis of variance (ANOVA) technique.

$55.01 \%$ contribution of xanthan gum being the most effective and dominant material in the maximization of coating weight value (see Figure 14). As it is mentioned in the above section, the main effect of xanthan gum on coating weight is similar to the case on apparent viscosity. Therefore, it can be obtained 
that the optimal mix proportion for maximization of coating weight is $0.25 \% \mathrm{~A}, 1 \% \mathrm{~B}, 0.3 \% \mathrm{C}$, and $0.6 \% \mathrm{D}$.

FR was improved when the contents of sodium stearate and polyacrylamide were increased in mixed solution but the increasing of xanthan gum and blender content decreased FR (see Figure 12). The sequence of significance for four materials in terms of friction reduction is $\mathrm{C}>\mathrm{A}>\mathrm{D}>\mathrm{B}$. The optimal mix proportion for maximization of friction reduction is $0.75 \% \mathrm{~A}, 0.75 \% \mathrm{~B}, 0.3 \% \mathrm{C}$, and $0.2 \% \mathrm{D}$.

It can be seen in Figure 13 that increasing the content of polyacrylamide and xanthan gum increased the contact angle of mixed solution while the increasement of blender decreased it. According to analysis, polyacrylamide is the most effective material on contact angle under the interaction effect. The optimum mix-designs for maximization of contact angle are $0.5 \% \mathrm{~A}, 1 \% \mathrm{~B}, 0.3 \% \mathrm{C}$, and $0.2 \% \mathrm{D}$.

By rights, there should be the same mix-design for all of these properties but it can be seen that the mix proportions in Table 2 are different from each other. Nevertheless, according to the analysis, an improvement effect in FR can be obtained by adjusting sodium stearate and polyacrylamide, while an improvement in apparent viscosity or coating weight can be achieved by adjusting xanthan gum; and the improvement in contact angle can be obtained by adjusting polyacrylamide.

In conclusion, with the aim of mainly reducing the friction between concrete bulk and the inner wall of pipes, the formula of the mass content for different material in the new concrete pump primers solution can be determined at $0.5 \%$ sodium stearate, $0.75 \%$ xanthan gum, $0.3 \%$ polyacrylamide, and $0.4 \%$ blender, that is, $\mathrm{A}: \mathrm{B}: \mathrm{C}: \mathrm{D}=1: 1.5: 0.6: 0.8$ in terms of mass ratio, and total ratio relative to water of the new primers is about $2 \%$.

3.5. Measurement of Performance of New Primers. In order to verify the performance of new primers with the optimum mix proportion, relevant experiments were conducted to check whether the friction reduction, coating weight, apparent viscosity, and contact angle can really reach the better level we want. In addition, the strength tests of shotcrete with the new primers were also performed.

3.5.1. Tolerance to Concrete and Its Properties. Given that fresh concrete has a large amount of dissolved salts and high alkalinity that may be a hostile environment against a concrete pump primers, and as the new primers travel through the pipes, they are generally exposed to concrete and cement residue. Therefore, the new primers must be able to withstand the alkalinity of concrete and tolerate when exposed to concrete or cement without breaking down.

To evaluate the ability to withstand concrete, the new pump primers were mixed with cement water that have the same alkalinity of fresh concrete. And the apparent viscosity, coating weight, FR, and contact angle of the solution with $2 \%$ primers were measured again.

As shown in Table 3, the verification study results of new primers with tap-water showed that the proposed optimum mix-design proportion basically reached the better level expected in terms of comprehensive aspects when comparing with the previous data. It also can be seen that the new
TABLE 3: Influence of mixed water type on the performance of new primers.

\begin{tabular}{lcccc}
\hline $\begin{array}{l}\text { The type of } \\
\text { mixture } \\
\text { water }\end{array}$ & $\begin{array}{c}\text { Apparent } \\
\text { viscosity } \\
(\mathrm{mpa} \cdot \mathrm{s})\end{array}$ & $\begin{array}{c}\text { Coating } \\
\text { weight } \\
\left(\mathrm{kg} / \mathrm{m}^{3}\right)\end{array}$ & FR (\%) & $\begin{array}{c}\text { Contact } \\
\text { angle }\left(^{\circ}\right)\end{array}$ \\
\hline $\begin{array}{l}\text { Tap-water } \\
\begin{array}{l}\text { Cement } \\
\text { water }\end{array}\end{array}$ & 104 & 0.32 & 31 & 69.4 \\
\hline
\end{tabular}

primers are resistant to concrete since various properties of the new primers mixed with cement water still remain nearly the same as those mixed with tap-water.

3.5.2. Effect of New Primers on Strength. It is difficult that no drop primer is mixed in fresh concrete in site, hence, in order to evaluate the effect of the new primers on the strength of concrete. Compressive strength measurements were conducted. Strength tests were divided into two groups: $C_{0}$ (without primers) and $C_{1}$ (mixing primers). Test procedure consisted of two parts.

In the first part, fresh concrete with or without primers was directly cast into three $100 \times 100 \times 100 \mathrm{~mm}$ steel moulds; therein, the new primers with $2 \%$ content (relative to tapwater) were mixed forcibly in fresh concrete during $5 \mathrm{~min}$ for $C_{1}$ specimens. In the second part, new primer solution was firstly pumped through pipes before pumping wet-mix shotcrete; then, fresh concrete mixed or not with $2 \%$ new primers was pumped and sprayed into an iron box mould with dimensions of $450 \times 350 \times 120 \mathrm{~mm}$ at the beginning of spraying. After 1-day curing at standard curing chamber with temperature of $20 \pm 2^{\circ} \mathrm{C}$ and $95 \%$ relative humidity, all specimens were demoulded. The large concrete slabs were subsequently cut into standard cube specimens with dimensions $100 \times 100 \times 100 \mathrm{~mm}$ after 7 days of curing. Finally, all specimens were cured at standard condition to 28 days as per Chinese Standards of GB 50086-2001. The uniaxial compressive strength of specimens was measured using a WDW3100 computer-controlled electric universal test machine. Mix proportion is shown in Table 4 and the results are listed in Table 5.

Table 5 shows that the $28 \mathrm{~d}$ compressive strength of shotcrete with new primers (average $40.3 \mathrm{MPa}$ ) was lower than that of white shotcrete (average $40.83 \mathrm{MPa}$ ), but the difference was not significant and can be neglected. In addition, the $28 \mathrm{~d}$ compressive strength of samples after shotcreting is higher than that before shotcreting, and the result is similar to the reports in literature [45].

\section{Field Application}

The new concrete pump primers established were applied at a shotcrete site in the simulated roadway of Shandong Wit Laboratory Mine Equipment Co., Ltd. The solution with new concrete pump primers prepared (about $100 \mathrm{~L}$ solution with $2 \mathrm{~kg}$ primers for $100 \mathrm{~m}$ pipes according to the average $5 \mathrm{~mm}$ thickness of lubrication layer reported in $[13,14]$ ) was firstly pumped through steel pipes to precreate the lubricating layer before pumping fresh concrete. 
TABLE 4: Mix proportion of wet-mix shotcrete.

\begin{tabular}{lcccccc}
\hline Number & Water-binder ratio (\%) & Sand $\left(\mathrm{kg} / \mathrm{m}^{3}\right)$ & Gravel $\left(\mathrm{kg} / \mathrm{m}^{3}\right)$ & Cement $\left(\mathrm{kg} / \mathrm{m}^{3}\right)$ & Silica fume $\left(\mathrm{kg} / \mathrm{m}^{3}\right)$ & New primers $(\%)$ \\
\hline$C_{0}$ & 0.5 & 1012 & 587 & 385 & 34 & - \\
$C_{1}$ & 0.5 & 1012 & 587 & 385 & 34 & 2 \\
\hline
\end{tabular}

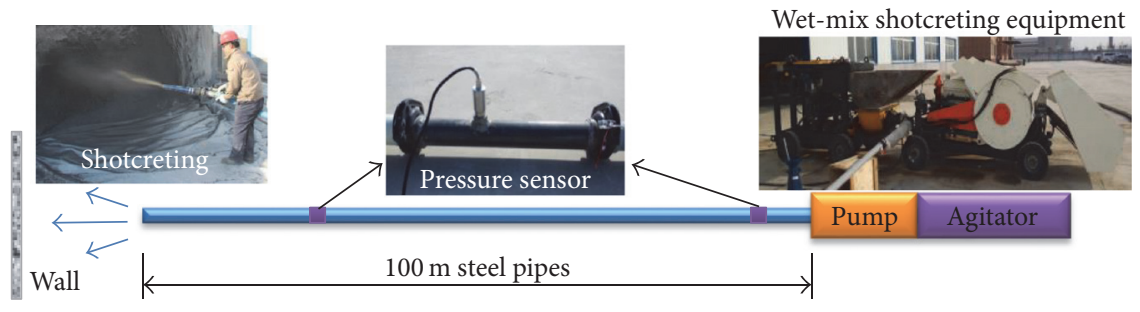

FIGURE 15: The site of wet-mix shotcrete.

TABLE 5: Results of compressive strength of shotcrete.

\begin{tabular}{lccc}
\hline Number & $C_{0}$ & $C_{1}$ & Average value (MPa) \\
\hline${\text { Before pumping }(\mathrm{MPa})^{*}}^{*}$ & 38.6 & 38.1 & 38.35 \\
${\text { After shotcreting }(\mathrm{MPa})^{*}}^{*}$ & 43.1 & 42.5 & 42.8 \\
Average value $(\mathrm{MPa})$ & 40.85 & 40.3 & \\
\hline
\end{tabular}

${ }^{*} 28 \mathrm{~d}$ compressive strength.

A common concrete pump primers weer used to compare the application effect in terms of friction reduction. Therein, the efficiency of friction reduction can be expressed indirectly by pipe pressure drop along pipeline that was calculated by measuring two points where pressure sensors were installed. The site of wet-mix shotcrete is shown in Figure 15. For a given flow rate, pressure drop reduction is taken to be one minus the ratio of the pressure drop required to pump fresh concrete $\Delta P i$ to the case without concrete pump primers $\Delta P_{0}$; that is, $\mathrm{PDR}=\left(1-\Delta P i / \Delta P_{0}\right)$; the larger the PDR, the better the pumping concrete.

In order to explore the time-varying effect of primers during pumping, the PDR were measured and calculated every 5 minutes after starting shotcrete. The result in Figure 16 indicates the comparison of PDR-time variations between new and common primers. Two types of primers all reduced the pressure drop to different extents. In the early 10 minutes, two primers all presented a dramatic decline trend. But the pressure drop reduction of new primers was about 1.5 time larger than that of common primers, and the stability of new primers was relatively higher than common primer; the effective time of the common primers is within $10 \mathrm{~min}$ and new primers within $30 \mathrm{~min}$.

On the other hand, with increasing pump time, primers would gradually disappear while the other lubrication layers consisting of cement paste or mortar would be formed slowly. As shown in Figure 17, the viewport is an interface under threaded joint where a pressure sensor connects with pipe wall. The interface can show the situation of lubrication layer after uninstalling the pressure sensor. Just after inserting new primers and before pumping fresh concrete, some viscous primers were observed at the interface shown in Figure 17(a). During middle pumping, both lubrication layers of primers

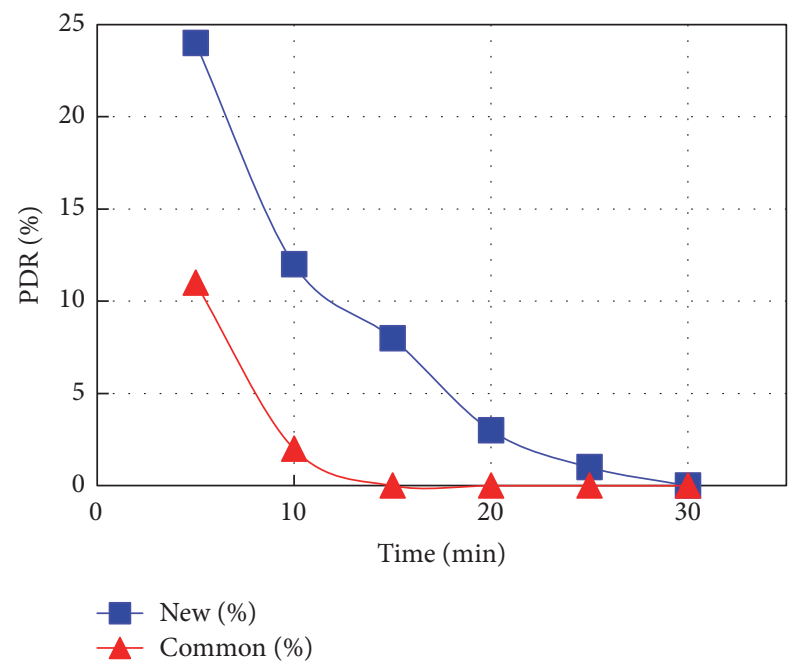

FIgURE 16: Influence of pump time on PDR.

and cement paste might exist simultaneously near pipe wall shown in Figure 17(b). After pumping wet-mix shotcrete and before cleaning pipes (30 minutes later), thin layer of cement paste was observed at this interface shown in Figure 17(c).

In addition, the effective time for reducing friction along pipeline is limited within 30 minutes; that is to say, there is no need to worry how to clean primers after pumping because general shotcrete engineering almost exceeds 30 minutes. If the pumping within short time (less than $30 \mathrm{~min}$ ) existed, it would be needed to enhance the pumping strokes with mortar sequentially to remove the residual primers.

As reported in $[1,2,4]$, the most important stage is the beginning of pumping. During this stage, once the lubrication layer containing cement paste or mortar is formed from fresh concrete (aggregate induced by high shear near pipe wall moving to pipe center), future pumping will be more easy and smooth. Hence, new primers still show effective application at the beginning of pumping for reducing friction.

Moreover, $100 \mathrm{~m}$ pipes were extended to $150 \mathrm{~m}$ and $200 \mathrm{~m}$, respectively, to discuss the effective length of pumping new primers. Certainly, the primer solution was increased in 


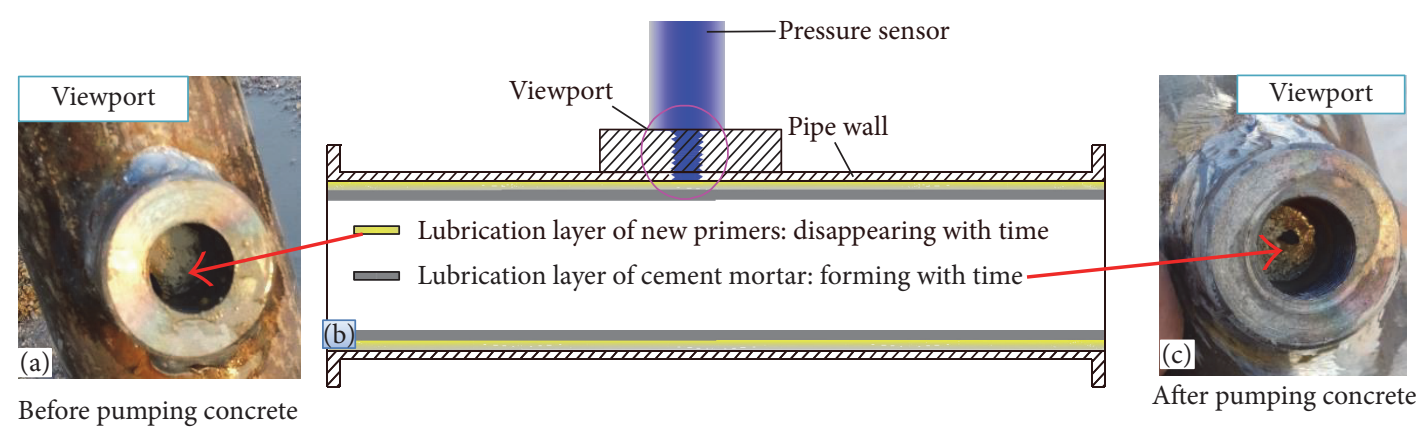

FIGURE 17: Change of lubrication layer with pump time.

proportion. Note that, before next test, pipes must be clean and dry. The PDR of $100 \mathrm{~m}, 150 \mathrm{~m}$, and $200 \mathrm{~mm}$ were $24 \%$, $22.7 \%$, and $20.3 \%$, respectively, during the first 5 minutes after inserting new primers, which shows that increasing pumping length decreased PDR slightly. It might be caused by the external resistance from more pipe joints along the longer pipeline. So we hardly concluded that the new primer can be effective no matter how long the pipeline is. Future study is needed in next paper. But it was clear that, within limited pumping length, new primers reduced the friction between bulk concrete and pipe wall at the beginning of pumping effectively when comparing with common primers. In addition, the composition of new primers is nonpoisonous and it is a kind of pollution-free production; at the same time, it reduced wear on equipment used when pumping wet-mix shotcrete.

\section{Conclusions}

Lubricating layer between concrete bulk and inner wall of pipe is very important for pumping fresh concrete successfully. In order to provide cost-effective pump primers instead of premium priced cement-based primers, a new type of pump primers were developed to precreate the lubricating layer.

Material A, sodium stearate, is the main lubricating constitution of the new concrete pump primers; $B$, xanthan gum, is the main viscous material; $C$, polyacrylamide, belongs to stable agent; and $\mathrm{D}$, absolute ethyl alcohol, is treated as blender. According to the combination experiments of sodium stearate with alcohol, xanthan gum, and polyacrylamide, orthogonal matching tests for A, B, C, and $\mathrm{D}$ were conducted, and the optimum formula of the new pump primers was determined. The mass content of each material was $0.5 \%$ sodium stearate, $0.75 \%$ xanthan gum, $0.3 \%$ polyacrylamide, and $0.4 \%$ blender, that is, $\mathrm{A}: \mathrm{B}: \mathrm{C}: \mathrm{D}$ $=1: 1.5: 0.6: 0.8$.

The properties of the new concrete pump primers were measured. Test results showed that they had the stable ability to withstand concrete and had few influence on compressive strength. When the content of the new concrete pump primers is $2 \%$, measured at a shotcrete site, two types of primers all reduced the pressure drop to different extents; in particular, the pressure drop reduction of fresh concrete with the addition of new primers was larger than that with the addition of common primers; that is, the new primers effectively reduced pressure loss at the beginning of pumping process.

\section{Competing Interests}

The authors declare that there is no conflict of interests regarding the publication of this paper.

\section{Acknowledgments}

The authors would like to acknowledge the team of wetmix shotcrete in College of Mining and Safety Engineering for the financial and technical support. They also appreciate Wit Laboratory Mine Equipment Co., Ltd., for the preparation and execution of tests. This work was supported by National Natural Science Foundation of China (Grant no. 51404145); Natural Science Foundation of China of Shandong Province (Grant no. ZR2013EEQ021); Applied Research Project Foundation of Qingdao Postdoctoral Researcher (Grant no. 2015176); Open Fund of the State Key Laboratory of Mining Disaster Prevention and Student Innovation Fund of College of Mining and Safety Engineering in SDUST (Grant no. KYKC17002).

\section{References}

[1] D. Kaplan, F. De Larrard, and T. Sedran, "Avoidance of blockages in concrete pumping process," ACI Materials Journal, vol. 102, no. 3, pp. 183-191, 2005.

[2] D. Feys, G. De Schutter, and R. Verhoeven, "Parameters influencing pressure during pumping of self-compacting concrete," Materials and Structures, vol. 46, no. 4, pp. 533-555, 2013.

[3] S. N. Aleekseev, "On the calculation of resistance in the pipes of concrete pumps," Mekhanizatsiya Stroitel'stva, vol. 9, no. 1, pp. 8-13, 1952.

[4] R. Weber, The Transport of Concrete by Pipeline, Cement and Concrete Association, 1968.

[5] D. Feys and K. H. Khayat, "Recent developments in evaluating pumping behavior of flowable and self-consolidating concretes," Journal of Sustainable Cement-Based Materials, vol. 4, no. 3-4, pp. 238-251, 2015.

[6] P. Jiabao, C. Yanhai, and Y. Jinyong, "Effect of heat treatment on the lubricating properties of lithium lubricating grease," RSC Advances, vol. 5, no. 72, pp. 58686-58693, 2015. 
[7] D. Feys, K. H. Khayat, A. Perez-Schell, and R. Khatib, "Development of a tribometer to characterize lubrication layer properties of self-consolidating concrete," Cement and Concrete Composites, vol. 54, pp. 40-52, 2014.

[8] D. Kaplan, F. De Larrard, and T. Sedran, "Design of concrete pumping circuit," ACI Materials Journal, vol. 102, no. 2, pp. 110117, 2005.

[9] M. S. Ingber, A. L. Graham, L. A. Mondy, and Z. Fang, "An improved constitutive model for concentrated suspensions accounting for shear-induced particle migration rate dependence on particle radius," International Journal of Multiphase Flow, vol. 35, no. 3, pp. 270-276, 2009.

[10] D. Feys, R. Verhoeven, and G. De Schutter, "Why is fresh selfcompacting concrete shear thickening?" Cement and Concrete Research, vol. 39, no. 6, pp. 510-523, 2009.

[11] L. Chen, G. Liu, W. Cheng, and G. Pan, "Pipe flow of pumping wet shotcrete based on lubrication layer," SpringerPlus, vol. 5, no. 1, article no. 945, 2016.

[12] M. S. Choi, S. B. Park, and S.-T. Kang, "Effect of the mineral admixtures on pipe flow of pumped concrete," Journal of Advanced Concrete Technology, vol. 13, no. 11, pp. 489-499, 2015.

[13] M. Choi, N. Roussel, Y. Kim, and J. Kim, "Lubrication layer properties during concrete pumping," Cement and Concrete Research, vol. 45, pp. 69-78, 2013.

[14] M. S. Choi, Y. J. Kim, and S. H. Kwon, "Prediction on pipe flow of pumped concrete based on shear-induced particle migration," Cement and Concrete Research, vol. 52, pp. 216-224, 2013.

[15] M. S. Choi, Y. J. Kim, K. P. Jang, and S. H. Kwon, "Effect of the coarse aggregate size on pipe flow of pumped concrete," Construction and Building Materials, vol. 66, pp. 723-730, 2014.

[16] H. D. Le, E. H. Kadri, S. Aggoun, J. Vierendeels, P. Troch, and G. De Schutter, "Effect of lubrication layer on velocity profile of concrete in a pumping pipe," Materials and Structures, vol. 48, no. 12, pp. 3991-4003, 2015.

[17] Y. Sohn, J. Lee, and S. Lee, "Application of ultra-high-strength concrete for high-rise building," in Proceedings of the 7th International Symposium on Advancement of Cement and Concrete Industries, vol. 2010, pp. 105-125, 2010.

[18] R. J. Phillips, R. C. Armstrong, R. A. Brown, A. L. Graham, and J. R. Abbott, "A constitutive equation for concentrated suspensions that accounts for shear-induced particle migration," Physics of Fluids A, vol. 4, no. 1, pp. 30-40, 1992.

[19] S. D. Jo, C. K. Park, J. H. Jeong, S. H. Lee, and S. H. Kwon, "A computational approach to estimating a lubricating layer in concrete pumping," Computers, Materials and Continua, vol. 27, no. 3, pp. 189-210, 2012.

[20] S. Jacobsen, L. Haugan, T. A. Hammer, and E. Kalogiannidis, "Flow conditions of fresh mortar and concrete in different pipes," Cement and Concrete Research, vol. 39, no. 11, pp. 9971006, 2009.

[21] N. Guptill, D. Akers, C. Bognacki et al., "Proposed reportplacing concrete by pumping methods," ACI Materials Journal, vol. 92, no. 4, pp. 441-464, 1995.

[22] K. E. von Eckardstein, Pumping Concrete and Concrete Pumps: A Concrete Placing Manual, Schwing, 1983.

[23] S. H. Kwon, C. K. Park, J. H. Jeong, S. D. Jo, and S. H. Lee, "Prediction of concrete pumping: part I-development of new tribometer for analysis of lubricating layer," ACI Materials Journal, vol. 110, no. 6, pp. 647-655, 2013.

[24] G. Ojeda, Concrete Pump Primers Performance Characteristics and Evaluation, Fritz-Pak, Dallas, Tex, USA, 2006.
[25] D. P. Montgomery, "Composition for and method of pumping concrete," Google Patents; 1995.

[26] L. Shijun, Z. Wenqi, Z. Jing, P. Lirong, H. Gang, and W. Peng, "Research and application of lubricant for concrete pumping pipe," Concrete, vol. 8, pp. 112-113, 2008.

[27] X. Zhou, Y. Huang, and J. Chen, "Application of concrete pump primer on pump trucks," in Proceedings of the 4th Session of National Special Concrete Technology, pp. 113-114, China Civil Engineering Society concrete quality Specialized Committee, Guizhou, China, 2013.

[28] Z. Kun, H. Gang, W. Gui, G. Qingxia, and T. Wanrong, "A type of lubrication for pumping concrete and its application," China patent 200910272623.3. 2012.

[29] G. Nieuwenhuys, Effect of drag-reducing polymers on a vertical multiphase flow [M.S. thesis in Applied Physics], Delft University of Technology, Delft, Netherlands, 2003.

[30] R. Marmy, A. Hayder, and M. Rosli, "Improving the flow in pipelines by Cocos nucifera fiber waste," International Journal of Physical Sciences, vol. 7, no. 26, pp. 4073-4080, 2012.

[31] B. R. Solomon, K. S. Khalil, and K. K. Varanasi, "Drag reduction using lubricant-impregnated surfaces in viscous laminar flow," Langmuir, vol. 30, no. 36, pp. 10970-10976, 2014.

[32] D. P. Montgomery, "Composition for and method of pumping concrete," Google Patents; 1997.

[33] J. Yao and J. Dong, "Evaluation of sodium stearate as a synergist for arylamine antioxidants in synthetic lubricants," Thermochimica Acta, vol. 262, no. C, pp. 157-163, 1995.

[34] H. Nie, W. Xu, J. Ren et al., "Impact of metallic stearates on disproportionation of hydrochloride salts of weak bases in solid-state formulations," Molecular Pharmaceutics, vol. 13, no. 10, pp. 3541-3552, 2016.

[35] T. Kamiya, H. Kondo, H. Hiroma et al., "Impact of process parameters on $\mathrm{Mg}-\mathrm{St}$ content and tablet surface wettability in the external lubrication method for a rotary tablet press," Advanced Powder Technology, vol. 27, no. 1, pp. 193-198, 2016.

[36] M. C. M. Farias, C. A. L. Santos, Z. Panossian, and A. Sinatora, "Friction behavior of lubricated zinc phosphate coatings," Wear, vol. 266, no. 7-8, pp. 873-877, 2009.

[37] H. Ono, H. Okabe, and M. Masuko, "Promotion of anti-wear property of sodium stearate by oxygen and surface active agents," Tribology Transactions, vol. 38, no. 3, pp. 693-699, 1995.

[38] X. Chen, W. Li, Q. Zhao, C. Selomulya, X. Zhu, and H. Xiong, "Physical and oxidative stabilities of $\mathrm{O} / \mathrm{W}$ emulsions formed with rice dreg protein hydrolysate: effect of xanthan gum rheology," Food and Bioprocess Technology, vol. 9, no. 8, pp. 1380-1390, 2016.

[39] I. G. Mandala, T. P. Savvas, and A. E. Kostaropoulos, "Xanthan and locust bean gum influence on the rheology and structure of a white model-sauce," Journal of Food Engineering, vol. 64, no. 3, pp. 335-342, 2004.

[40] P. Adhikary and R. P. Singh, "Synthesis, characterization, and flocculation characteristics of hydrolyzed and unhydrolyzed polyacrylamide grafted xanthan gum," Journal of Applied Polymer Science, vol. 94, no. 4, pp. 1411-1419, 2004.

[41] G. Zhou, W. Cheng, and S. Cao, "Development of a new type of alkali-free liquid accelerator for wet shotcrete in coal mine and its engineering application," Advances in Materials Science and Engineering, vol. 2015, Article ID 813052, 14 pages, 2015.

[42] J. Yang, D.-D. Liu, B.-J. Liu, M.-M. He, and Y.-F. Wang, "Research on mine dustfall agents based on the mechanism of wetting and coagulation," International Journal of Minerals, Metallurgy and Materials, vol. 21, no. 3, pp. 205-209, 2014. 
[43] J. Mackenzie, D. M. Martinez, and J. A. Olson, "A quantitative analysis of turbulent drag reduction in a hydrocyclone," Canadian Journal of Chemical Engineering, vol. 92, no. 8, pp. 14321443, 2014.

[44] J. D. Smith, R. Dhiman, S. Anand et al., "Droplet mobility on lubricant-impregnated surfaces," Soft Matter, vol. 9, no. 6, pp. 1772-1780, 2013.

[45] K.-K. Yun, S.-Y. Choi, and J. H. Yeon, "Effects of admixtures on the rheological properties of high-performance wet-mix shotcrete mixtures," Construction and Building Materials, vol. 78, pp. 194-202, 2015. 

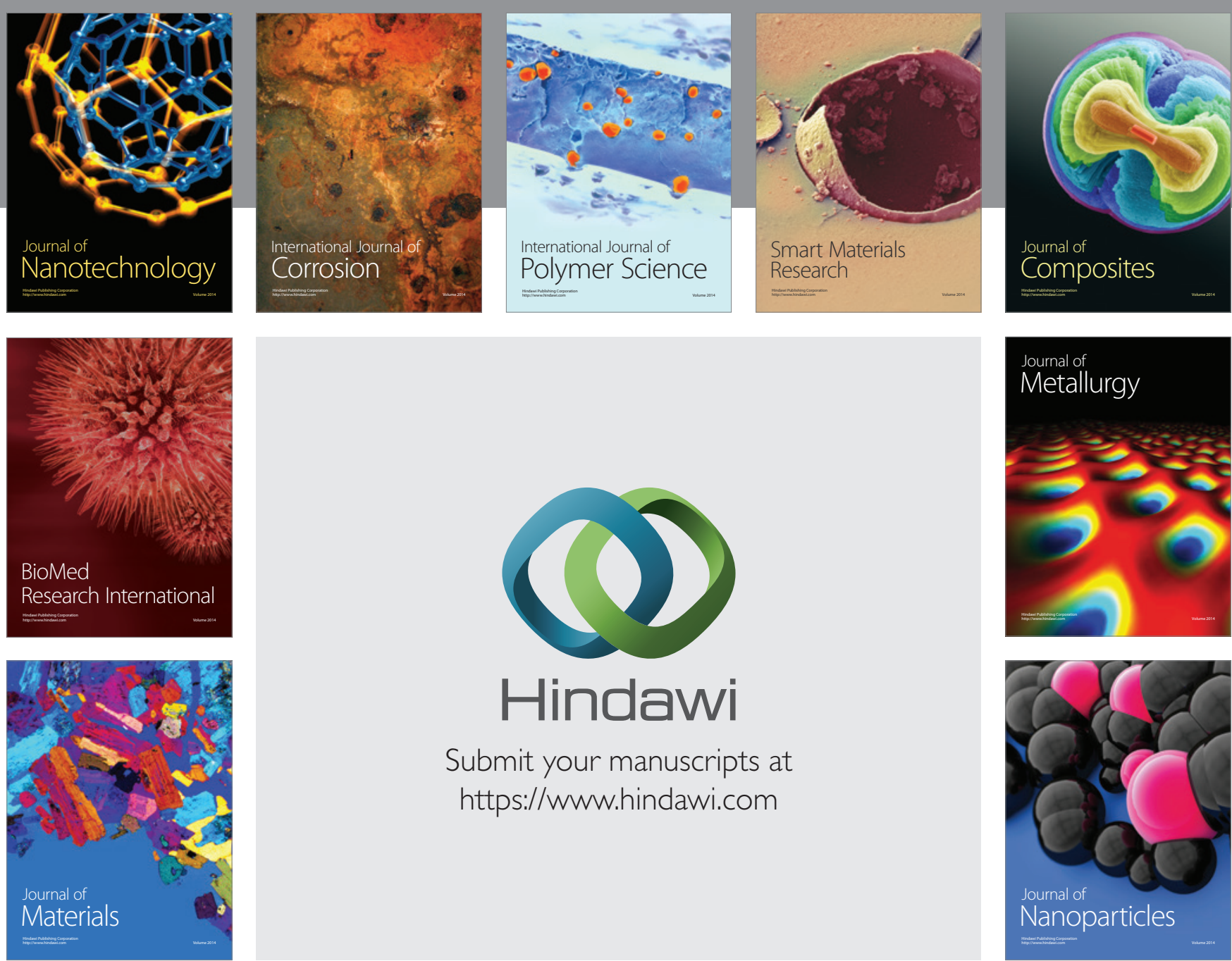

\section{Hindawi}

Submit your manuscripts at

https://www.hindawi.com

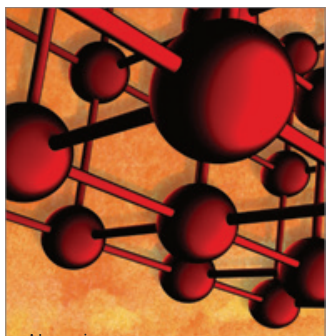

Materials Science and Engineering
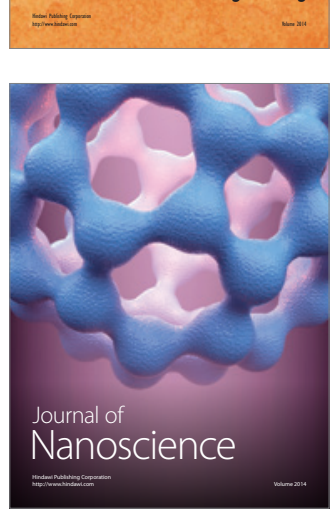
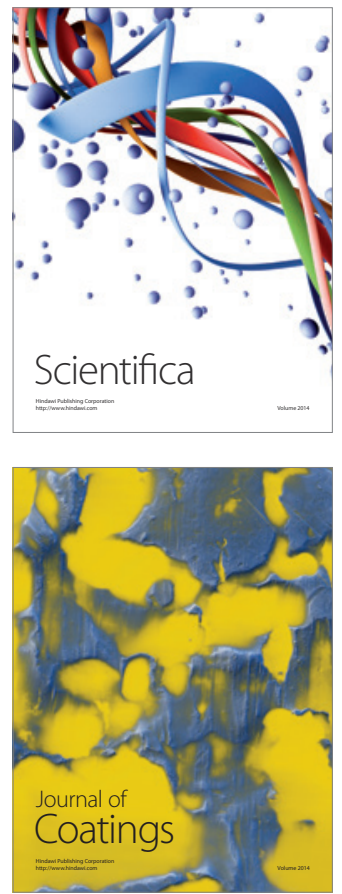
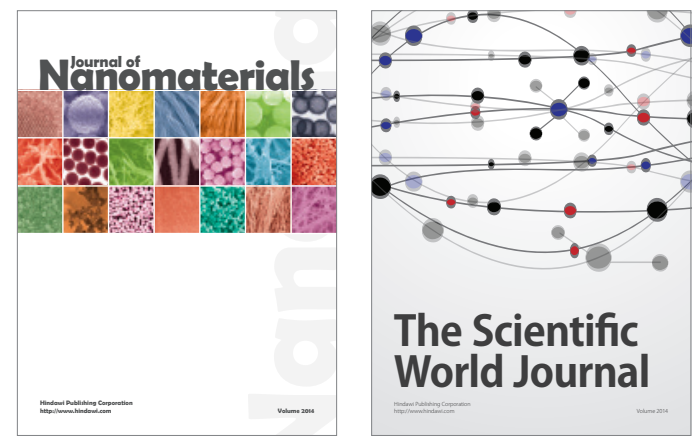

The Scientific World Journal
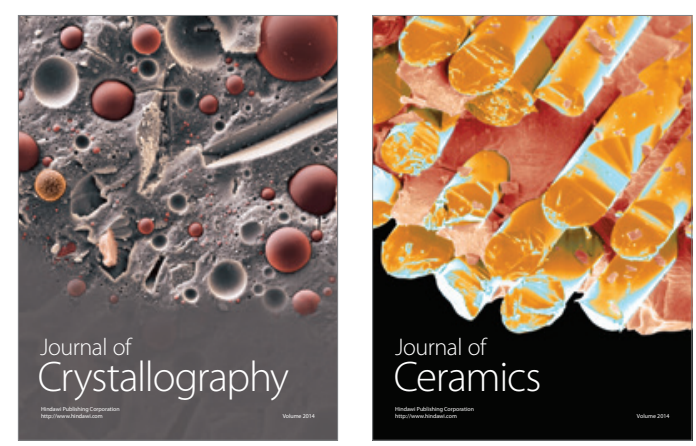
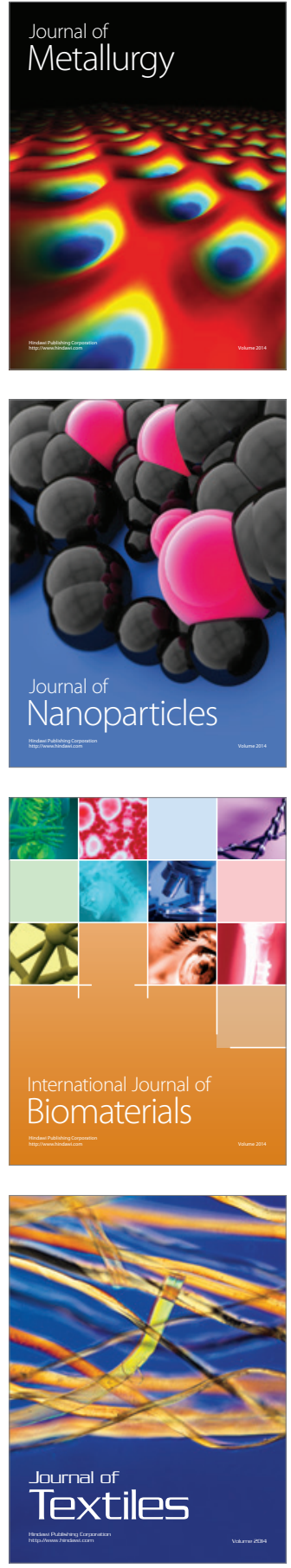